\title{
Hemangiossarcoma renal unilateral em cão
}

\author{
Renal unilateral hemangiosarcoma in dog \\ Sônia Rumiko Suzuki' ${ }^{1}$, Lanucha Fidelis da Luz Moura' ${ }^{1}$, Geraldo do Prado Siqueira ${ }^{1}$, \\ Ricardo Fuso Camargo ${ }^{1}$, Lívia Aparecida D'Avila Bitencourt Pascoal ${ }^{1}$, Lívia Maria de Souza Rocha ${ }^{2}$, \\ Angélica do Rocio Carvalho Silva² \& Helder Esteves Thomé ${ }^{3}$
}

\begin{abstract}
RESUMO
O hemangiossarcoma é um tumor mesenquimal maligno com origem nas células endoteliais dos vasos, podendo ser primário em qualquer tecido. As neoplasias renais, pos sua vez, são raras, podendo causar sinais locais ou sistêmicos de insuficiência renal. Um canino da raça boxer, com cinco anos de idade e $24 \mathrm{~kg}$ foi atendido no Hospital Veterinário Vicente Borelli (HOVET) da Fundação de Ensino Octávio Bastos (UNIFEOB), com histórico de hiporexia, emese e cansaço fácil. Ao exame ultrassonográfico, constatou-se a presença de uma massa dorsal no rim direito e de estruturas anecóicas mal definidas no baço. Procedeu-se laparotomia exploratória com retirada da massa renal e realização de nefrectomia, esplenectomia e ovariosalpingohisterectomia. O material retirado adjacente ao rim foi identificado como hemangiossarcoma renal, todavia os demais órgãos não apresentaram células neoplásicas. Apesar da bibliografia afirmar que frequentemente as neoplasias renais malignas têm envolvimento bilateral, no animal em questão, isso não ocorreu, sendo o objetivo do presente trabalho relatar essa apresentação incomum de hemangiossarcoma.
\end{abstract}

Descritores: hemangiossarcoma, rim, neoplasia, cão, nefrectomia.

\begin{abstract}
Hemangiosarcoma is a malignant mesenchymal tumour that has its origin in endothelial cells of blood vessels, and can be primary in any tissue. Renal neoplasms, in it's turn, are rare and can cause local or systemic signs of renal insufficiency. A canine of boxer breed, five years old and $24 \mathrm{~kg}$ was presented to the Hospital Veterinário Vicente Borelli (HOVET) of Fundação de Ensino Octávio Bastos (UNIFEOB). The history included hiporexia, emesis and weakness. The ultrasonographic assessment showed a growth dorsal to the right kidney and unclear anechoics structures on spleen. An exploratory laparotomy was performed, and nephrectomy, splenectomy and ovariohysterectomy were realized. Once the renal growth was removed, it was identificated as renal hemangiosarcoma. The other organs didn't have neoplasic cells at histological assessment. Although bibliography reports that malignant renal neoplasms are frequently bilateral, in this animal it doesn't occurred. The aim of this paper is to report this unusual presentation of renal hemangiosarcoma.
\end{abstract}

Keywords: hemangiosarcoma, kidney, neoplasm, nephrectomy.

${ }^{1}$ Programa de Residência do Hospital Veterinário Vicente Borelli (HOVET), Fundação de Ensino Octávio Bastos (UNIFEOB), São João da Boa Vista, São Paulo, Brasil. ${ }^{2}$ Clínica Cirúrgica de Pequenos Animais do HOVET, UNIFEOB. ${ }^{3}$ Serviço de Patologia do HOVET, UNIFEOB. CORRESPONDÊNCIA: L.F. Moura [lanucha_moura@ @erra.com.br]. 


\section{INTRODUÇÃO}

O hemangiossarcoma é um tumor mesenquimal maligno com origem no endotélio dos vasos, podendo ser primário em qualquer tecido, baço, átrio direito e fígado, os órgãos mais acometidos nos animais domésticos $[2,7,9]$. Em tecido ósseo ou subcutâneo e nos rins costumam ocorrer menos frequentemente [1].

Neoplasias renais primárias são incomuns nos cães e gatos, respondendo por de 0,6 a $1,7 \%$ das neoplasias descritas, geralmente sendo malignas em ambas as espécies [1]. As neoplasias mesenquimais primárias dos rins também são consideradas raras, sendo que as mais freqüentemente diagnosticadas são o fibroma e fibrossarcoma, seguidos pelo hemangioma e hemangiossarcoma [6]. Os sinais clínicos mais comuns da enfermidade incluem anorexia, depressão e perda de peso, mas ocasionalmente a única anormalidade observada é o aumento de volume abdominal devido à presença da massa renal [1].

O presente trabalho tem por objetivo relatar um caso de hemangiossarcoma renal de apresentação unilateral diagnosticado em um cão da raça boxer.

\section{RELATO DE CASO}

Foi atendida no HOVET-UNIFEOB, uma cadela da raça boxer, com cinco anos de idade, pesando $24 \mathrm{~kg}$ e apresentando histórico de hiporexia, um episódio de emese e cansaço fácil. Ao exame físico, foi constatada presença de cifose, mucosas levemente pálidas, dor à palpação da região hipogástrica lateral direita, frequência cardíaca de 140 batimentos por minuto, taquipnéia, tempo de preenchimento capilar de 2 segundos, temperatura retal de $38,3^{\circ} \mathrm{C}$ e hidratação aparentemente normal. Ao exame ultrassonográfico foi observada a presença de massa complexa

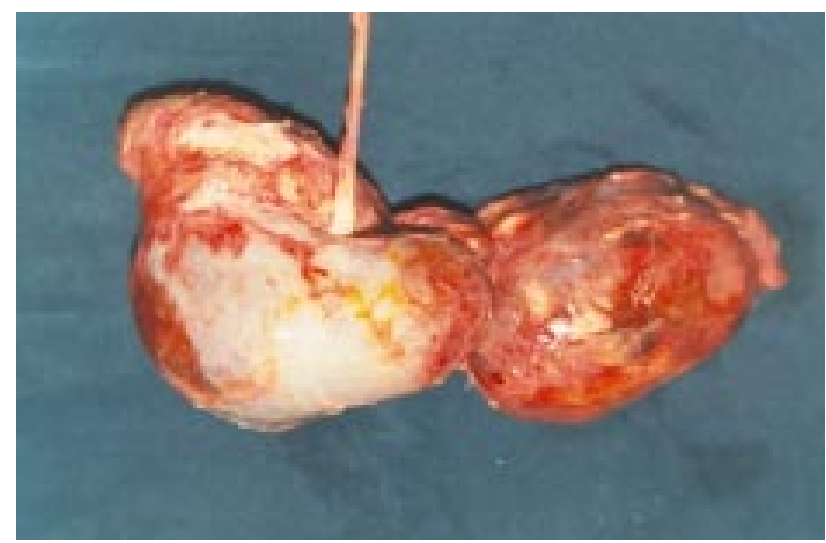

Figura 1. Aspecto do rim direito após nefrectomia, com a presença de massa envolvendo-o e se projetando caudalmente. dorsal ao rim direito com 5,44 centímetros $(\mathrm{cm})$ de diâmetro, sugestiva de neoplasia. O baço apresentava estruturas anecóicas, tortuosas, intercomunicantes e mal definidas, enquanto que os demais órgãos abdominais não apresentavam alterações ultrassonográficas. O hemograma demonstrou uma anemia normocítica normocrômica com anisocitose e linfopenia. A avaliação bioquímica das funções renal e hepática apresentava-se dentro dos valores normais para a espécie.

$\mathrm{Na}$ evidência de tais achados, o animal foi submetido à cirurgia de laparotomia exploratória. Durante o ato cirúrgico, optou-se pela realização de uma esplenectomia, devido à presença de massas irregulares no órgão, e ovariosalpingohisterectomia, uma vez constatada a ocorrência de áreas hiperêmicas e congestas no útero. Adicionalmente, foi procedida nefrectomia e retirada da massa que envolvia o rim direito e se estendia caudalmente ao mesmo (Figura 1).

Após o procedimento cirúrgico, os órgãos foram encaminhados ao Serviço de Patologia para exame. Macroscopicamente, notou-se a presença de massa neoplásica de aproximadamente $15 \times 7 \mathrm{~cm}$, localizada em polo renal cranial direito e projetando-se com áreas císticas repletas de sangue caudalmente ao órgão (Figura 2). Histologicamente, observou-se a ocorrência de formações vasculares preenchidas por sangue, constituídas de grande quantidade de células poligonais a ovóides, com núcleos grandes e hipercromados, citoplasma escasso, com diversas figuras de mitose (Figura 3), diagnosticando-se que se tratava de um hemangiossarcoma renal. No baço, a cápsula e a porção subcapsular superficial apresentaram focos de necrose e reação inflamatória granulomatosa do tipo corpo estranho, adjacentes a fragmentos de material amarelado refringente, congestão, discreta hemossiderose e

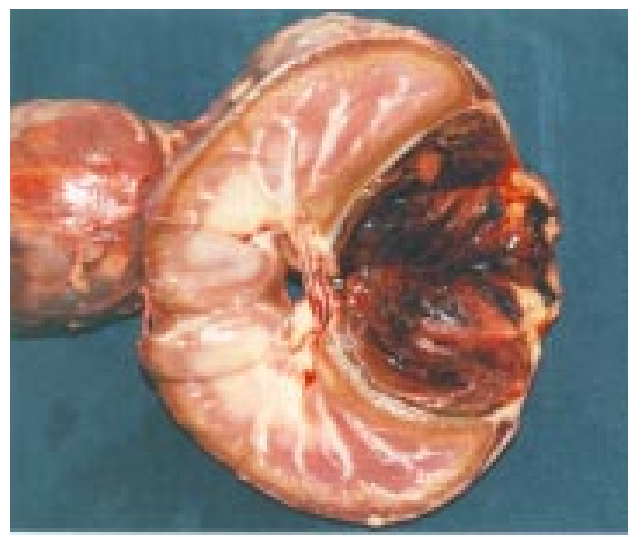

Figura 2. Área cística com conteúdo sanguinolento adjacente ao rim. 


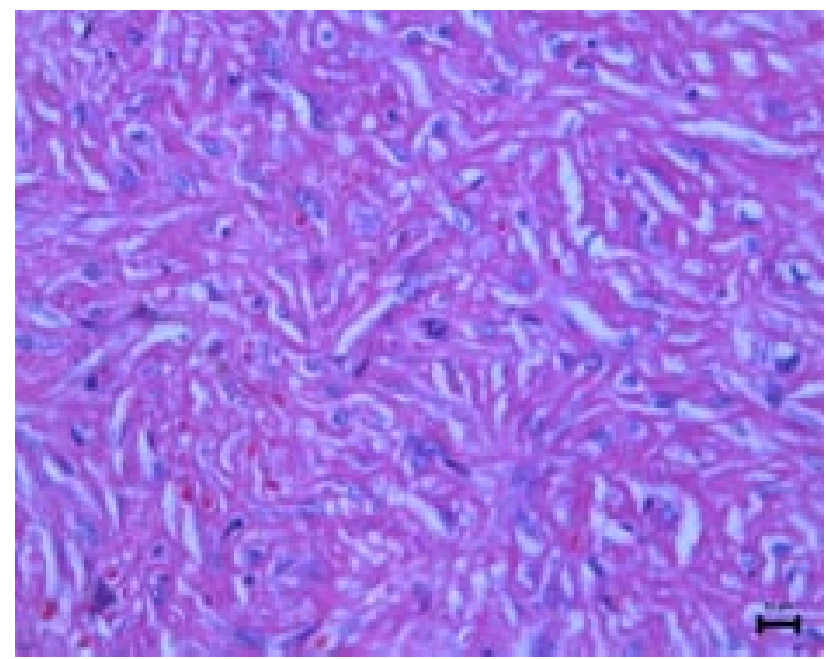

Figura 3. Células poligonais a ovóides, com núcleos grandes e hipercromados, citoplasma escasso, com figuras de mitose.

grande quantidade de megacariócitos. Adicionalmente, o útero apresentava intensa hemorragia em miométrio e perimétrio. Todavia, nos demais órgãos, com exceção do rim, não foram encontradas células neoplásicas.

Durante o período pós-operatório, o animal permaneceu recebendo fluidoterapia intravenosa por três dias, tendo seu débito urinário monitorado, e constatando-se produção de um volume normal. Os testes bioquímicos de função renal demonstraram valores dentro dos parâmetros normais para a espécie, e durante os meses que se seguiram o animal teve seu estado clínico acompanhado, não vindo a apresentar quaisquer alterações até o momento do presente relato.

\section{DISCUSSÃO}

As neoplasias renais são raras, podendo causar sinais locais ou manifestações sistêmicas de insuficiência renal, todavia, no presente caso, não foi observada azotemia, provavelmente pelo fato de o comprometimento renal ser unilateral [1].

O hemangiossarcoma, na maioria dos casos, parece ser de natureza espontânea, não possuindo uma etiologia identificada, e podendo acometer qualquer órgão, inclusive os rins, onde se encontrava a neoplasia do paciente relatado [1,2,7]. No coração, é o tumor mais comum de cães, envolvendo átrio ou aurícula direita e podendo causar metástases [7,9]. Em humanos, a sobrevida observada é de 3 a 9 meses, sendo que estas neoplasias também já foram descritas em camundongos, equinos e suínos [3,4,5,8]. Geralmente o rim é local de metástase de vários tipos de neoplasias primárias, incluindo os hemangiossarcomas. Apesar de neoplasias primárias envolvendo fígado, baço e pulmões frequentemente serem responsáveis pela ocorrência de metástases renais, no animal em questão, não se evidenciou a presença de células neoplásicas no baço, embora este macroscopicamente se encontrasse alterado $[1,7,9]$.

Apesar da literatura descrever frequentemente o envolvimento renal bilateral no caso de neoplasias malignas, no paciente relatado, se observava a presença de massa tumoral envolvendo somente o rim direito, o que pode ter contribuído, ou mesmo ter sido decisivo, para a sobrevida do animal [1].

Com este trabalho fica relatado o diagnóstico de hemangiossarcoma renal unilateral em um cão, embora seja raro o desenvolvimento primário desta neo-plasia no órgão em questão. $\mathrm{O}$ envolvimento de outros sítios primários não pode ser descartado, todavia, visto que alterações foram evidenciadas ao exame macroscópico, apesar da ausência de células neoplásicas ao exame microscópico.

\section{REFERÊNCIAS}

1 Fossum T. 2001. Cirurgia de Pequenos Animais. São Paulo: Roca, 1338p.

2 Hammer A. 2004. Hemangiossarcoma. In: Rosenthal R.C. (Ed). Segredos em Oncologia Veterinária. Porto Alegre: Artmed, pp.253-260.

3 Iglézias J.C.R., Velloso L.G.C., Dallan L.A., Benvenuti L.A, Verginelli G. \& Stolf N.A.G. 2000. Angiossarcoma de átrio direito. Revista Brasileira de Cirurgia Cardiovascular. 15: 186-191.

4 Morrow J.L. 2002. Hepatocellular carcinoma and suspected splenic hemangiosarcoma in a potbellied pig. Canadian Veterinary Journal. 43: 466-468.

5 Pille F., Van Anrooij M., Martens A., Van Brantegem L., Desmet P. \& Gasthuys F. 2004. Severe lameness and muscular swelling due to intramuscular hemangiosarcoma in a horse. Vlaams Diergeneeskundig Tijdschrift. 73: 131-134.

6 Serakides R., Sant'ana F.J.F., Carneiro R.A. \& Lavalle G.E. 2000. Leiomiossarcoma pulmonar e renal em cão: relato de caso. Arquivo Brasileiro de Medicina Veterinária e Zootecnia. 52: 45-55. 
7 Tilley L.P. \& Smith Junior F.W.K. 2003. Hemangiossarcoma esplênico e hepático. In: Tilley L.P. \& Smith Junior F.W.K. (Eds). Consulta veterinária em 5 minutos - espécies canina e felina. 2.ed. São Paulo: Manole, p.764.

8 Werner P.R., Chiquito M. \& Pachaly J.R. 1998. Estudo retrospectivo das neoplasias diagnosticadas em animais selvagens ou exóticos pelo serviço de patologia do hospital veterinário da Universidade Federal do Paraná entre 1974 e 1996. Archives of Veterinary Science. 3: 39-44.

9 Woodard J.C. 2000. Sistema Esquelético. In: Jones T.C. (Ed). Patologia Veterinária. 6.ed. São Paulo: Manole, pp.913961. 